\title{
Life saving intervention in the neonatal period: dilemmas and decisions
} University of Bristol,
Southmead Hospital

\author{
P M Dunn
}

In defending a patient's rights, whether it be 'to have prenatal diagnosis', 'to have a caesarean section', or 'to submit to lifesaving interventions', we must never lose sight of that most fundamental right of all-the right of choiceand the right not to have what doctors sometimes assume that patients will or should want. The right to die, or more specifically the right to die with dignity, concerns the right to refuse life sustaining treatment which is a burden, which prolongs the act of dying, and which is not in the interest of the patient.

As adults of sound mind, surely few would dispute a person's individual rights in this matter, but supposing he has had a severe stroke, and is paralysed, incontinent, semiconscious, and without hope of recovery? In such circumstances I hope that my doctor and my nearest and dearest relations would agree not to embark on long term life support, or, if it was already in use, that they would be prepared to withdraw it.

Somewhat similar circumstances exist in respect to the newborn infant who is unable to express an opinion, and whose interests have therefore to be represented by the parents and their medical advisors. These life and death decisions are difficult and stressful; the parents are emotionally involved. They may have only a vague idea of the long term outlook for their child and the implications for their family. They may wish and indeed should be encouraged to seek advice from others, whether from friends and relations or from their own religious, legal, or medical advisors. Likewise the doctor will be wise to seek the views of other members of the health care team, and to obtain a second opinion from a senior colleague. Ultimately, though, the final decision should, I believe, be discussed and reached in private between the parents and their physician.

I am aware of the contrary view that such decisions should be decided by ethics committees. Experience shows, however, that committees tend to be ponderous and insensitive and may err on the side of continued life support. In addition, the wider debate and publicity that often results may cause great distress to the already grief stricken family. Certainly, though, in countries with medicolegal problems and constraints, ethics committees may help to protect the individual doctor and in these circumstances I can understand their value.

The withholding of lifesaving care may be considered in three broad groups of newborn infants: those with severe malformations, those with severe hypoxic or traumatic brain damage, and those of extreme prematurity with serious problems such as severe periventricular haemorrhage and bronchopulmonary dysplasia. In such circumstances the doctor should carefully explain the situation and outlook to the parents, as well as the management options. Often he will not be seeking a decision from them but rather trying as sensitively as possible to gain insight about their wishes as to the management of any life threatening event.

A number of factors require careful consideration. How will the longevity of the infant be affected by the use or withdrawal of full medical care? What quality of life is the child likely to have? This must take into account not only the nature of the disability (mental or physical), but also its degree of permanence and the likely amount of suffering. The impact of the problem on the family, though less important, cannot be ignored, nor can the availability of medical and other supporting resources. An experienced doctor should know in advance and take into account the parents' likely response if and when he advises against the use of intensive care. The decision should be based primarily on the interests of the child. I always try to take the initiative in advising the withholding of intensive care, and thus spare the parents the stress and burden of actually making the decision. If they do not agree, as occasionally happens, then I respect their wishes and continue with full life support.

On other occasions, in contrast, the doctor may recommend intensive care or an operation which the parents then decline. When this happens I ask myself the following five questions: Do the parents understand the clinical condition and prognosis of their child? Do they wish or should they consult others before finally making up their minds? Do they require more time? Is their decision a loving, caring one made in the interests of their child? And finally: Is their decision a reasonable one in the interests of their child and, if in doubt, is it so unreasonable as to renuest them to seek other medical advice or for me to take legal steps to take the child into care under the protection of the courts?

In 35 years' practice with newborn infants I can only recollect one instance when the parents of a child in my care refused potentially lifesaving treatment for their baby-an exchange transfusion for severe jaundice. It was against the parents' religious beliefs. Legal permission was granted to over-ride their objections. I am still uncertain as to whether this course of action was ethically correct even if it was medically justified. In giving advice about ethical dilemmas, doctors should be careful not to impose their own cultural and religious prejudices on 
those whose beliefs and practices may be different from their own bearing in mind, though, the requirements of the law.

The personal qualities required by doctors who help parents to reach acceptable decisions in these ethical dilemmas are compassion, humility, and courage. Doctors must be prepared to accept that they will occasionally make mistakes and they must be prepared to live with their doubts. As William Osler wrote: 'Errors of judgement must occur in an art which consists largely of balancing probabilities.' Thus it is inevitable that we will wonder and question from time to time the correctness of some of the decisions we have made. These doubts we must shoulder-it is part of our job-but in order to spare parents the unbearable burden of these same doubts, it may sometimes be necessary to give our views and advice with greater firmness and conviction than we may feel. When appropriate, this is a part of being a good doctor.

Based on a paper presented to a Symposium on Ethics in Human Reproduction at the World Congress of Gynecology and Obstetrics, Rio de Janeiro, October 1988. 